\title{
The Interpretation of Hetu and Luoshu
}

\author{
Sun Yanzhe \\ Faculty of Foreign Languages, Henan University of Science \& Technology, Luoyang City, 471000, Henan Province, China
}

Received November 1, 2019; Revised June 5, 2020; Accepted June 16, 2020

Copyright $\odot 2020$ by authors, all rights reserved. Authors agree that this article remains permanently open access under the terms of the Creative Commons Attribution License 4.0 International License

\begin{abstract}
Hetu and luoshu, or the Yellow River trigrams and the Luo River trigrams, also the first mystical images in Chinese graphemic culture, are regarded as the origin of Heluo culture and feature prominently in the history of Chinese culture and Chinese thoughts. Many researchers of different dynasties expounded the sign of the image after the appearance of hetu and luoshu by Chen Tuan. The evolution of hetu and luoshu differed from the general process of symbolic evolution because its significance arose before its image. This particularity is due to the highly comprehensive and highly commensurable nature of hetu and luoshu as a meta-sign. According to the nearly archaeological excavation and using the methodology of "one vigor and four elements", this paper makes the interpretation of its graphic which reflects the wisdom of ancient Chinese philosophy. The interpretation will be analyzed as following: Yin-Yang five-elements, the harmonious relationship between man and nature, meta-sign and the means of image-numerology in Hetu and Luoshu. A thorough study of Hetu and luoshu may help understand the evolution of Chinese nation, Chinese national character, beliefs and orientation of social life, and help clarify the deep historical roots of cultural communication, cultural psychology and spiritual orientation.
\end{abstract}

Keywords Hetu and Luoshu, Philosophical Thought, Yin- Yang Five-elements, Meta-sign

\section{Introduction}

Hetu and Luoshu is a mysterious figure that was passed down from ancient China. It is considered to be the origin of Heluo culture and the source of Chinese culture. Since the beginning of the Qin Dynasty, Hetu and Luoshu have been recorded in the document literature. In the Zhou Book of Change, there is a survey: "As for the Dragon Map out of the Yellow River and the Tortoise Script out of the Luo River, the sages in imitation invented the eight trigrams and the nine-square numerical grid". [1]Some modern scholars believe that this Hetu and Luoshu is not the one with black-and-white image produced by Song Dynasty. But as we know, the Song Confucianism has become the ruling ideology of the whole society after the Song Dynasty. Hetu and Luoshu have been recorded in the first page of The Four Books (The Great Learning, The Doctrine of the Mean, The Confucian Analects, and The Works of Mencius) and The Five Classics (The Book of Songs, The Book of History, The Book of Changes, The Book of Rites and The Spring and Autumn Annals). Their influence is deeply rooted in the Chinese culture in the past millennium. So many scholars study it on the basis hereby. The excellent traditional culture is the spiritual lifeblood of the Chinese nation and the wisdom of their ancestors in building Chinese characteristics. It will have values in the great practice of socialism.

\section{Schools of Studies of Hetu and Luoshu}

From the Song and Yuan dynasties onto the Ming and Qing dynasties, the metaphysical meaning-principle school became gradually popular. During the Song and Yuan dynasties, with the spreading of Taoist Chen Tuan's Hetu and Luoshu images, the school of image and numerology and the school of meaning and principles became popular. Scholars such as Chen Tuan and Shao Yong stressed image, numerology and meaning in Hetu and Luoshu. Studies in later ages refer to two images by Chen Tuan of the Song Dynasty. [2] His work was named Dragon Map. But this map can't be found any more. Its preface is preserved in Song Wen jian (Lv Zuqian, Song Dynasty) which expounds the theory of taking numbers as graphs. Two factions occupied the society, one is Liu Mu and the other is Shao Yong. In the Yi shu gou yin tu, Liu used combinations of diagrams and text to argue that numbers underlay, and provided the keys to understand the development of the cosmos and the creation of the myriad entities that inhabited it. He further asserted that the important role 
numbers played in the process of creation and transformation was revealed to the ancient sage $\mathrm{Fu} \mathrm{Xi}$ via two important diagrams, the Hetu and Luoshu. The main difference is as following: Liu mu believed that Hetu and Luoshu are all given by Fu xi. He thought Hetu has 9 dots and Luoshu 10 dots. Shao yong believed that Hetu is given by Fuxi and Luoshu is awarded to Da yu (the third of the three legendary emperors who created the Chinese state) while Hetu has 10 dots and Luoshu 9 dots. Zhu xi and Cai Yuan ding inherited and carried forward Shao yong's theory. Zhu Xi (1130 1200) as one of the most significant philosophers of the Neo-Confucian school in the Song and the Ming dynasties, he held that the universe has two aspects: the formless and the formed. Many kinds of Hetu and Luoshu figures appeared. As the Yuan, Ming and Qing dynasties pursued Zhu Xi's philosophy, Hetu and Luoshu with black-and-white spots by Zhu Xi (figure1) are considered as the real one from time immemorial. There have been many changes in later ages. Mao Qiuling and $\mathrm{Hu}$ wei in Qing dynasty put forward a new theory and challenge Hetu and Luoshu by Zhu. These new statements are personal. People in that time were not convinced by them.

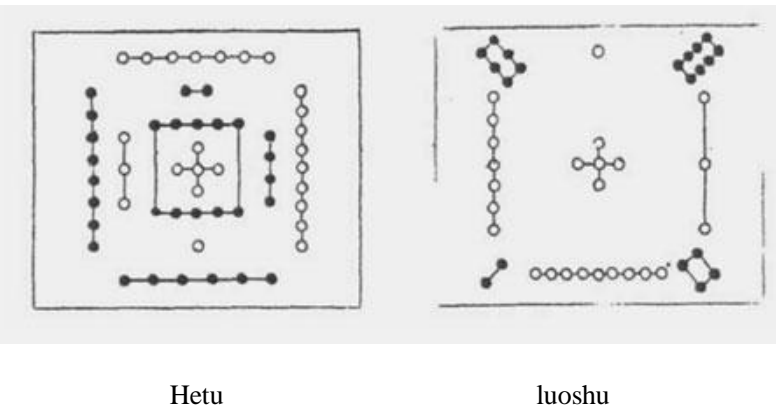

Figure 1. Hetu and Luoshu by Zhu Xi,1182m

The figure above of Hetu and Luoshu is from Zhu Xi's book "The Original meaning of Zhouyi". Zhu Zi's interpretation of Hetu and Luoshu has a strong mysticism and subjective side effects. In the book "Enlightenment of Yixue", Zhu Zi believed: "Hetu has 10 pots, and luoshu 9 pots, which is the number of Da Yan. "Obviously, Zhu Zi's words above are all for the purpose of supplementing" the number of Da Yan. "However, Zhu Zi's comparatively systematic and comprehensive interpretation of the meanings represented by Hetu and Luoshu is unprecedented.

Hetu and Luoshu have a very close relationship with Zhu $\mathrm{Zi}$ 's philosophy. It can be said that $\mathrm{Zhu} \mathrm{Zi}$ laid the foundation of his philosophical system through the elaboration of Hetu and Luoshu, and thus pushed the Confucian tradition of the theory of Yin and Yang to the highest point.[3]

Many disputes over the Hetu and Luoshu continued through thousands of years. It can be proved by archaeology. In 1977, in Fu yang of Anhui province, in the tomb of the Ru yin marquis in the Western Han Dynasty, a piece of "Taiyi Palace was unearthed." The schema was exactly the same as the "Luoshu's Number", so Hetu and Luoshu is definitely not the baseless conjecture by the Song Dynasty. In 1987, the rectangular plate jade unearthed in the Dawenkou cultural tombs at Ling jiatan of Hanshan City in Anhui Province was engraved with symbols representing Tian yuan, Bei chen, Fourdimensional, Octagonal, Eighth, and Eight Diagrams. According to this, Cai Yunzhang believed that the four, five, nine, and five small round holes drilled around the jade version respectively fitted the description in "Easy-Dried Chiseling".

Hetu and Luoshu have tremendous cultural potential. The images create unique visual effects. The arrangements of numbers indicate order and the relationship between numbers. All these messages conveyed in Hetu and Luoshu epitomize the essence of ancient Chinese culture and reflect ancient Chinese people's cognition of the objective world.

\section{Analysis Perspectives}

The content of Hetu and Luoshu is a mystery. Therefore, we can analyze it by "one vigor and four elements" methodology. An important feature of Chinese ancient culture is that it has a moral heart to understand the wisdom taught by his ancestors. The Chinese ancestors recognized the world by understanding of the image- numerology and meaning-pattern "One vigor" is the morality. The image-numerology helps us see through the appearance to the essence. The statistic is to transform and turn the formula patterns into mathematics. The theory is based on the observation of phenomena and the projection of mathematical models. Qi is an energy form after the transformation in life. According to Wang Yongkuan [4], Hetu and Luoshu should be regarded as an ancient and famous cultural achievement. Hetu and Luoshu's related phenomenon should be regarded as a rich cultural concept. Hetu and Luoshu is the most classic ancient Chinese traditional culture and is the root of Heluo culture. It contains the Chinese traditional philosophy, the politics, the medicine, aesthetics and astronomy. In the history of hinese philosophy, the content expressed by Hetu and Luoshu shows the Chinese philosophy.

From the point of regulatory meta-sign, the evolution of hetu and luoshu differed from the general process because its significance arose before its image. This particularity is due to the highly comprehensive and highly commensurable nature of hetu and luoshu as a meta-sign. It is also a kind of regulatory meta-sign with historical continuity and regionality. The interpretations of the cosmic law reflect the efforts of people, as well as the inheritance and continuity culture, contributed to the construction of hetu luoshu as a meta-sign. 


\section{Interpretation by Philosophical Thoughts}

\subsection{Philosophical Thought of "Yin - Yang and Five- Elements"}

The core system of Chinese traditional culture is the Yin-yang theory. Since this theory is metaphysical, its production and deduction must be based on the model. The development and application of the theory should be based on the model. From ancient times to nowadays, different people have their own theoretical models. The principle of rigorous inheritance and the historical evidence which related to the yin and yang doctrines appear broken, fragmented, and even dislocated. So we tried to set up the model of Hetu and luoshu by using the ancient yin and yang doctrine in the process of dissemination and inheritance.

The model of Hetu and luoshu is derived from the distribution of yin and yang in the following two figures (Figure 2). From a three-dimensional perspective, Hetu and luoshu is a whole, a flat representation of a three-dimensional model. This three- dimensional model is a double-helical structure which is symmetrical and opposite in direction. Hetu is a top view of the model, and Luoshu is a front view of the model.
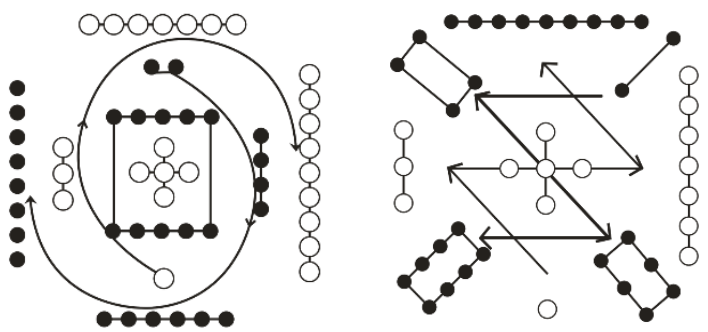

Figure 2. Model of yin-yang in Hetu and Luoshu

In the eyes of the founders of yin-yang system, everything has its causes and effects in change, and this change has certain rules. For Hetu and luoshu, the use of yin and yang, gossip model as a sentence, can reflect the simple principles of yin and yang theory.

Hetu is a process of sequential transformation between primary and secondary aspects of contradiction. Luoshu is a process of mutation in the primary and secondary aspects of contradiction. The sequence transformation and mutation transformation are the base of natural law of death and sickness.

Inaction and promising are all nature law. Yang in the left and Yin in the right are also nature law. From ancient time till nowadays, Hetu and Luoshu has become the symbol language in the world which does not need to be translated. The structure of Hetu is like this: one and six located in the north, two and seven are in the south, three and eight in the east, four and nine in the west, five and ten in the middle. One to five are known as "Sheng shu", six to ten are known as "Cheng shu". [5] The numbers signify the interdependence of five elements. Yin-yang are born inside. Yin and Yang increase and decrease. Yin is the passive, female cosmic principle in Chinese dualistic philosophy. Yang is the active, masculine cosmic principle in Chinese dualistic philosophy. Heaven and earth are a mighty forge where hidden forces flame. And all things in the Universe came from Nature's anvil.

Luo Shu is known as "nine-rectangle-grid". Its structure is as follows: Five is in the center. It represents the mutual promotion and mutual restraint. One and Six which mean "water" can restrain "fire" with number Two and Seven. The fire can restrain "Metal" with number Four and Nine. The "Metal" can restrain the "Wood" with Three and Eight. The "wood" can restrain the "Earth" with number Five. The odd numbers are multiplied by three. "Yang" rises and falls. The even numbers are multiplied by Two (as shown in the figure 3). Yin and Yang rising and falling reflect the movement of things. The "earth" in the middle plays a harmonic role. The summation of vertical and horizontal slopes is fifteen. This reflects the relative balance and relative stability of all things.

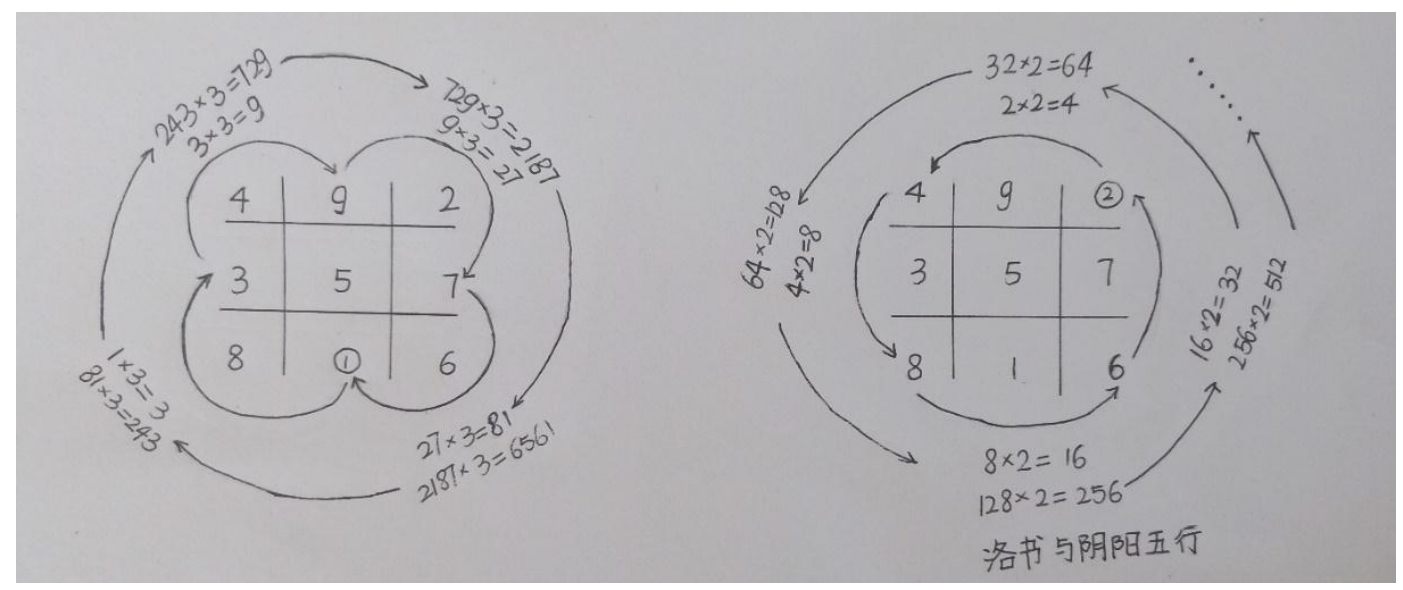

Figure 3. Numbers of Hetu and Luoshu reflect the Yin- Yang and five- elements 
Hetu and Luoshu contain the principles of the yin-yang and five -elements. By mastering the rules of yin-yang and five- elements, we can reconcile yin and yang and gain an insight into the meaning of Tao. This idea is more common in ancient architectural structures. Beijing's architecture is built on the Meridian of the Imperial Palace's Tai he temple. The Summer Palace has 17-hole bridges (counting from both sides to 9 holes), and the ancient astronomical calendar is also relevant. [6]

\subsection{The Philosophical Thought of "Theory That Man Is an Integral Part of Nature" for Thousands of Years, Harmonious Idea Is the Main Idea That Chinese Pursues}

Hetu and Luoshu just showed the philosophical thought of "theory that man is an integral part of nature". Many scholars believe that Hetu and Luoshu are the source of Zhouyi. "The theory that man is an integral part of nature" is a reflection of the harmony between human beings and the nature. [7] Under this notion, Chinese has formed distinctive thought, behavior way and had eternal running after harmony between man and nature. Moreover, some scholars equate the theory to another that man is an integral part of nature and inquire constantly into the meaning of the theory that heaven and man unite as one to resolve the present environmental crisis. Thirdly, in the universal value, the "theory that man is an integral part of nature", "theory that putting oneself in the place of another" of the pre-Qin Confucian management thoughts, plays an important role in the communication of different civilization. Chinese thinkers held the theory that man coheres with nature. They were opposed to the separation of man from nature. That man is an integral part of nature is the most fundamental concept in ancient Chinese philosophy and is the basic spirit of Chinese culture. Such concept has always exerted influence upon the thinking mode, behavior mode and aesthetic mentality of Chinese nationality.

The black and white points in Hetu and Luoshu just showed the unity of opposites between Yin-yang and the universe. It reflected the idea of harmony between man and nature. For example, the numbers in vertical and horizontal of Luoshu are 15. Many Chinese architecture adopted this style. To uphold the theory, we should protect physical environment, facilitate ecological civilization and build a world of sustainable development.

\subsection{Numerical Worship}

The Chinese ancestors have a numerical worship. A cross-culture analysis of the social values and cultural notions that are involved in number worship will help with in-depth studies of the area. "One" a first number in Hetu and Luoshu legend, just like what said by Lao Zi "Tao gave birth to the One; the One gave birth successively to two things, three things, up to ten thousands. Everything has a bright and a dark side, co-existent in harmony."[8] In the
Chinese culture, the number five is abstracted as numeral worship target. The ancient people thought that five indicates the completeness and harmony. All things are based on the theory of five elements. The mystery of the number seven from the original in fact is a large part of the worship of ancestors of the Big Dipper, the worship of that time in extreme natural environment and ignorance of the primitive society to the formation of China. So seven is also a numeral worship for Chinese people. [8] Of course, the number Nine is important. It has kinds of symbolic meanings, for example, we called the emperor "imperial throne", there is a nine-headed bird (a fabulous bird whose appearance was formerly regarded as a bad omen). All the conceptions of numerical worship are embodying in Hetu and Luoshu which has the numbers representing its meanings and the connotation.

\subsection{Meta-sign of Hetu and Luoshu}

The prefix "meta-" means originally "behind" in Greek. Philosophy is considered to be a deep discussion of the laws of the natural sciences. Therefore, "meta-" refers to the discussion of the law, and the meta-symbol is the "symbol of symbols". Zhao Yiheng believes that the sign is meaningful, meta-sign is meaningless.(Zhao yiheng, 2012) Therefore, meta-symbol can be understood as a certain meaning reproduction.

The evolution of Hetu and luoshu is very special. In the Song Dynasty, Hetu and luoshu became two pictures with specific images. After different interpretations, the two pictures were different in the fields of geomantic omen, medicine, mathematics, chinese characters and astronomy. The initial process of obtaining the meaning of Hetu and luoshu is intuitive in form. The so-called initial is "first nature", which is temporary and intuitive, such as the visual impression of images and sounds. In the Song Dynasty, Hetu and luoshu appeared intuitively for the first time, because Hetu and luoshu is a meta symbol, the important role of which is to maintain these new symbols.

What kind of characteristics do Hetu and luoshu have to become a special meta- symbol?

Before the Song Dynasty, Hetu and luoshu was interpreted as a kind of auspicious. On one hand, everything is spiritual. On the other hand, it emphasizes the relationship between the hetu luoshuband the Eight Diagrams. It is the enlightenment of mathematical knowledge and the law of the universe. Therefore, the belief in the spirit and the understanding of the laws of the universe can be regarded as the consistent characteristics of Hetu and luoshu, and it is also the main reason for becoming a meta- symbol. People can understand the laws of nature and the law of the universe.

\section{Conclusions}

Hetu and Luoshu is a symbol of Chinese culture. Its 
connotation continuously changes in the long river of history. The soul of Hetu and Luoshu is the symmetry and neutrality of Yin-yang, which reveals the relationship between all things. As the President Xi Jinping said "The Chinese civilization has a unique value system for thousands of years. The excellent Chinese traditional culture has become the gene of the Chinese nation and is rooted in the hearts of the Chinese people. It has influence on the way of thinking and behavior of the Chinese people."[13] A thorough study of Hetu and Luoshu may help understand the evolution of Chinese nation, Chinese national character, beliefs and orientation of social life, and help clarify the deep historical roots of cultural communication, cultural psychology and spiritual orientation. The Chinese excellent traditional culture has an inherent relationship with the development of the Chinese nation and its vitality, cohesiveness, and creativity. We should make new definitions for the outstanding Chinese traditional culture in order to welcome a new era.

\section{Foundation}

No: [2016] -JKGHA-0012, Henan Provincial Social Science and Technology Federation Project: Chinese-foreign cultural identify of Hetu and Luoshu,

No: SKL-2016-754, 2016 Henan Science \& Technology

University Project: Hetu and Luoshu Culture Symbol External Propaganda Study.

No: 17YJC740065, 2017 Humanities and Social Sciences of Ministry Education Project: Chinese-foreign meta-sign cultural identify of Hetu and Luoshu.

\section{REFERENCES}

[1] Sun Shuntong. Source of Hetu-Annal of Long Ma Fu Tu Temple. 2th ed. Zhengzhou: Zhongzhou Ancient Books Publishing House; 1997.

[2] (Song Dynasty) Chen Tuan. Heluo Numerology.3th ed. Haikou: Hainan Press; 2015.

[3] Chen chao, Hetu luoshu and Zhouxi's philosophy [J]. Study of Zhouyi, 1995(4).

[4] Wang Yongkuan. Hetu Luoshu Quest [M]. Zhengzhou: Henan People Publishing House; 2006.

[5] (Qing Dynasty) Jiang Yong, Feng Leiyi. Heluo Essence [M]. Beijing: JiuzhouPress, 2011.

[6] (Qing Dynasty) Li Guangdi. An Eclectic Study of the Zhou Book of Change $[\mathrm{M}]$. Li Yixin collated. Beijing: JiuzhouPress; 2002.

[7] Li Xueqin, Zhao Jinzhao, Shi Shangang. Heluo Culture and Chinese I-Ching. 1th ed. Zhengzhou: Henan People Publishing House; 2009.

[8] Li Genzhu. Origin of Chinese Culture: Roots in Heluo.2th ed.
Changchun: Baishan Press; 2012.

[9] A Cheng. Luoshu and Hetu: An investigation into the Images of Civilization (Revised Edition) [M]. Beijing: Zhong Hua Book Company;2015.

[10] Wang Yongkuan. Hetu Luoshu Quest [M]. Zhengzhou: Henan People Publishing House; 2006.

[11] Wang Yongfu, Wu Xiuhui. The Approaches and Skills of Traditional Chinese Medicine Prescription: Hetu and Luoshu and Traditional Chinese Medicine (Second Edition) $[\mathrm{M}]$. Beijing: China Press of Traditional Chinese Medicine; 2013.

[12] Xue Xueqian. The Zhou Book of Change and Wave-Quantum Physics [M]. Shanghai: Chinese Science Corporation; 1937.

[13] Xu Jinxing, Guo Shaolin, Hu Gengtian. Comment on Heluo Culture $[\mathrm{M}]$. Beijing: Chinese Literature and History Press; 2014.

[14] Zhao yiheng, Semiology: principle and deducation, [M]. Nanjing: University of Nanjing Press; 2012.

[15] (United States) Jiao Weifang. The Book of Changes-Algebra in the Universe $[\mathrm{M}]$. Shanghai: Shanghai Scientific and Technological Literature Press; 1995.

[16] (United States) Wen haiming, development of Zhouxi's view on hetu and Luoshu,[J]. The study of Zhouyi, 2000(4).

[17] Li linxian, the model of Yin-yang in Hetu and Luoshu,[J].Western Journal,2018(3)

[18] Xia yuanhui, Historical Research on the Inheritance Chanels of Hetu and luoshu.[J].Journal of Henan university of Science and Technology,2019(10). 